\title{
What's in Your Backyard?
}

\author{
A Curriculum Guide to Accompany
}

The University of Oklahoma Citizen Science Soil Collection Program

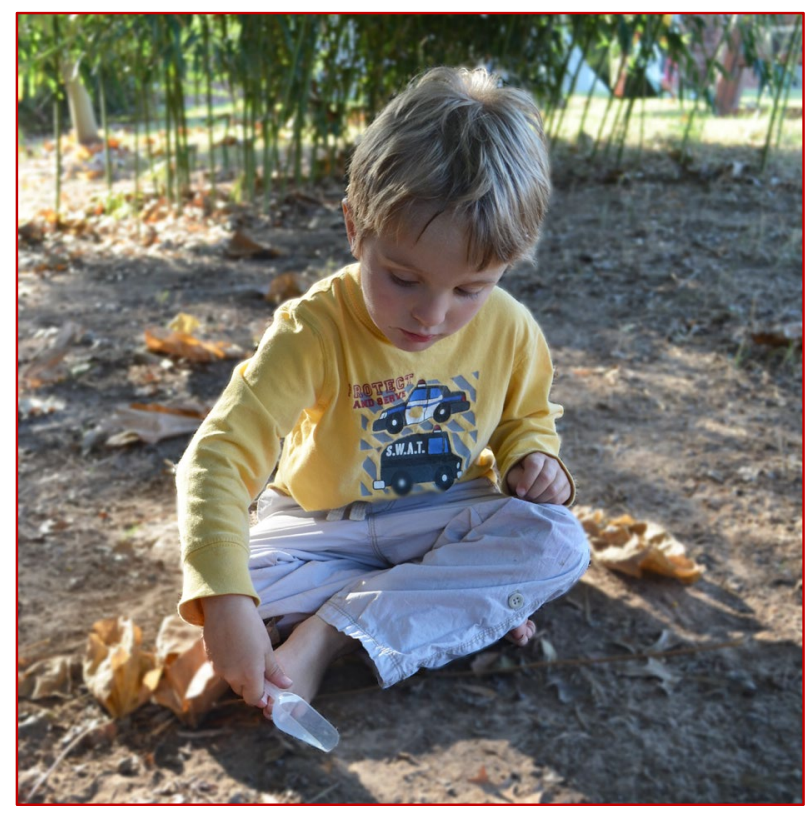

Integrating citizen science into the classroom. Designed for use with $4^{\text {th }}$ grade to high school students.

Maggie Shelton and Robert Cichewicz

The University of Oklahoma, Department of Chemistry and Biochemistry, Norman, OK U.S.A. 73019

DOI: $10.15763 / 11244 / 301393$

ISBN: 9781946659002

(C) 2018 Maggie Shelton and Robert Cichewicz

First Edition: August 8, 2018

Attribution-NonCommercial-ShareAlike 4.0 International (CC BY-NC-SA 4.0)

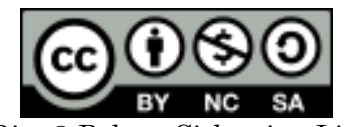

Cover Image: Child and Dirt (C) Robert Cichewicz. Licensed CC BY-NC-SA 4.0. https://whatsinyourbackyard.org/wp-content/uploads/2018/08/child_dirt_scoop3.jpg 


\section{What's in your backyard? \\ Curriculum guides for integrating citizen science into the classroom for students in grades $4^{\text {th }}$ through high school.}

The key to the next life-saving biomedical discovery might be living right below your feet. Dozens of fungi can occupy a single handful of soil and many of them are adept at making new compounds called natural products. These remarkable molecules hold tremendous promise for treating human diseases. - https: / / whatsinyourbackyard.org

\section{Dear Educators,}

Thank you for your interest in participating in the University of Oklahoma Citizen Science Soil Collection Program and the associated curriculum guides. This guide was designed to support educators by helping to integrate citizen science into the classroom environment. By including research about fungi in your classroom, you are helping to foster the development of scientific inquiry skills in students, while also contributing to cutting edge biomedical research being conducted at the University of Oklahoma.

The Citizen Science Soil Collection Program was first established in 2010 at the University of Oklahoma. As the foremost and only continuously operating program of its kind, the mission of the Citizen Science Soil Collection Program is to bring citizen scientists like yourself together with biomedical researchers in an effort to find new drug-like molecules from fungi. Research has revealed that soils are home to millions of unique fungi. Many of these fungi produce mixtures of molecules known as natural products that hold tremendous promise for development into new medicines. Biomedical researchers at the University of Oklahoma's Natural Products Discovery Group are using the fungi obtained from soil samples collected by citizen scientists to find new natural products that halt cancer cell growth, stop the spread of infectious pathogens, and kill life-threatening parasites. https: / / whatsinyourbackyard.org/about/

Each set of lessons in this guide was designed in correspondence with the scientific inquiry goals and concepts from the Next Generation Science 
Standards (NGSS). Suggested grade levels are present for each lesson, and are easily adjusted to meet the needs of older or younger students. These guides also are structured to fit a $5 \mathrm{E}$ learning cycle/instructional model format. ${ }^{1}$

We appreciate your participation as citizen scientists, which not only is critical for furthering scientific research, but also introduces key scientific concepts and thought processes to students. We invite you to continue you citizen science experience and learn more about the Citizen Science Collection Program at https://whatsinyourbackyard.org/about/. If you have any additional questions, please contact us at $\underline{\text { npdg@ou.edu. }}$

\section{Maggie Shelton}

(BS, Chemistry Education, University of Oklahoma, 2017)

\section{Robert Cichewicz}

(Director, University of Oklahoma, Citizen Science Soil Collection Program) 


\section{Table of Contents}

Section 1. Exploring Science (K-12)

Section 2. Exploring Fungi

$\left(4^{\text {th }}\right)$

Section 3. Decomposer Observer $\left(5^{\text {th }} \mathbf{6}^{\text {th }}\right)$

Section 4. Synthetic and Natural (Middle/High School)

Appendix/Further Resources

Worksheets
Page 3

Page 7

Page 14

Page 20

Page 26

Page 33 


\section{Section 1. Exploring Science (K-12)}

\section{Introduction}

Current STEM initiatives and changes in the K-12 standards, such as the development of the NGSS, highlight the increasing emphasis on science learning. It has become more important to introduce science to students at an earlier age. These changes come with their own unique challenges. It can be difficult to introduce science into the classroom - teaching inquiry methods, fostering logic, and introducing critical scientific thinking. Moreover, students may have preconceptions about the nature of science that can be limiting and discouraging. This module aims to make students aware of the positive contributions they can make to science right now and to build scaffolding that will encourage scientific interest and adherence to appropriate methodology.

\section{Background}

When asked to imagine a scientist, many children may be prone to stereotypical imagery based on what they have seen or heard on television, movies, and in books. These stereotypical images might include middle-aged (white) males in lab coats, surrounded by obscure equations on boards and strange, shiny scientific equipment. Many scientists do not fit this image. This misconception can be subconsciously limiting and discouraging to those that do not fit into that very specific set of criteria.

Through this lesson, we want to help students become aware that there are many kinds of scientific fields and scientists. In addition, there are many ways that each person can engage in science and become scientists! One of the easiest ways anyone can participate in scientific inquiry is by finding a citizen science project such as the University of Oklahoma, Citizen Science Soil Collection Program.

\section{Performance Goals}

Upon completion of this module, students should be able to understand some of the characteristics and "rules" of science that include:

- Scientific investigations use a variety of methods - there are many types of science and methods of doing science.

- Science is a human endeavor - there are many types of people that do science, and anyone can be a scientist. 


\section{Pre-Lesson Preparation - None}

\section{Materials}

- Citizen Science Soil Collection Program educators kit, which can be obtained here https://whatsinyourbackyard.org/educate

- Attached worksheet

- Internet access/projector for supplemental videos

\section{Optional Materials}

http://www.theteachertoolkit.com/uploads/documents/Accountable Talk Sent ence_Stems_template_elem.docx

In the classroom (1 hr)

Engage: With no prior discussion, students are provided the Exploring Science worksheet and asked to complete the first two questions. On the worksheet, students are asked:

1. What is science? In the space below, draw a picture of what you think science is.

2. What is a scientist? In the space below draw a picture of a scientist.

After a short time passes, students should be provided the opportunity to discuss what they drew. You may want to facilitate this discussion using the Accountable Discussions procedure from http://www.theteachertoolkit.com/index.php/tool/accountable-discussions.

Step 1: Students discussion in pairs: "I believe science is because...". Encourage them to develop a shared definition of what is science and what is a scientist.

Step 2: Pairs discusses their definitions in groups of 4. Groups are encouraged to develop a shared definition of what is science and what is a scientist.

Step 3: Continue the discussion as a class. During the discussion, students should be asked what they think "doing science" means. The aim of this activity is to broaden the students understanding of who scientists are and what doing science means. They should be scaffolded, if necessary, in developing an understanding that being a "scientist" is a broad term that applies to many people. We want to convince students that everyone can be a scientist, and that they are going to be scientists in this module! 
Explore: Students should be provided the soil collection kit in class. The instructions for the soil collection process are fairly simple, and do not require much in-depth discussion in class time. While this can be done in groups, it is beneficial to giving each child autonomy to go through the collection process themselves. Focus should be directed toward the process of selecting a location to collect the sample that meets the scientific criteria, as well as adherence to scientific procedure.

Important note - some restrictions may apply to doing the soil collection on a school's campus in relation to public vs. private land laws. Encourage students to collect a sample at their own homes. At home engagement and learning outside the classroom is beneficial for everyone involved and this is a great activity to encourage families to do science with their kids! It is also important that the collection form is filled out and signed so that each sample can be used for lab research. Refer to our website https://whatsinyourbackyard.org/ for details about collection guidelines and restrictions.

Note: This is a logical point to stop if you would like to split the discussion over two days. If you split days, the next science class period would begin with collecting the soil kits with samples from the students.

Explain: In this segment, students will be asked to explore what is citizen science. The teacher can ask students to think about questions such as "What is it? Why is it important?" and "Why might it be challenging?" Depending on the group of participants, the teacher can either provide their own definition of citizen science or attempt to facilitate students doing research to come up with their own. [e.g., citizen science is a scientific method in which the public works with professional scientists (often collecting or analyzing data) to address large and/or more complex objectives that are not attainable when acting alone].

Students should then be asked about the citizen science project why they want to join. Students may provide many types of answers. Some interesting discussion points can be obtained by reviewing a selection of citizen science stories on the website https://whatsinyourbackyard.org/csstories/. Based on the definition of citizen science, all students become citizen scientists through participation in the project. We urge teachers to encouraged students to take ownership via their project participation and to view this as their project!

Which scientists are a part of the citizen science project? The lab-based researchers and the citizen scientists! Citizen scientists like students and teachers are so vital to our project that they even have their own gallery on the 
website! (https://whatsinyourbackyard.org/csgallery/) In some cases, citizen scientists even make major discoveries themselves. One Dutch schoolteacher discovered a completely new type of astronomical object when participating in the Galaxy Zoo citizen science project. Another small group in Galaxy Zoo discovered a new more efficient type of galaxy, and another amateur astronomer found a new exoplanet.

It's not just adult participants in citizen science programs that make discoveries. When working with scientists or in science programs, kids can make discoveries as well. When kids are curious, innovative, and open to investigation, they have discovered things with significant applications in fields as varied as astronomy, archaeology, biology, and chemistry. Some examples of fantastic discoveries by kids can be found in the appendix section of this guide. Sharing these peer stories can be a huge motivator for children.

If our students have limited ideas about what science is, we lose out on a lot of their potential. Citizen science is helpful for your students to develop skills observing, questioning, planning, analyzing, and communicating.

Elaborate: There are many fantastic examples of visual content available relating to citizen science and science in general. Programs like Crash Course and SciShow (both standard content, and content designed for kids) provide extra learning materials in formats that are exciting to students and can be invaluable as supplemental resources for students.

If your class wishes to learn more about the power and history of citizen science, videos such as this one ${ }^{2}$ from Hank Green and SciShow are perfect.

Evaluate: After students complete the module, the students should complete question 3 of the worksheet. They should also be asked to discuss any changes in their responses or beliefs about science and scientists. The teacher should review and ask students to make sure to include their new definition of science as well. This definition can come from class discussion, from the instructor, or other inspirational sources at your disposal.

It would be ideal to guide students toward thinking about science as the following: Science can be defined as a process of collecting and organizing information, through observation and/or experimentation, to answer questions about the natural world.

Finally, students can be asked to draw a new picture of what a scientist is. (Younger students may need to be encouraged to draw a picture of themselves doing science.) 


\section{Section 2. Exploring Fungi (4 $4^{\text {th }}$ Grade)}

\section{Introduction}

Structure and function are fundamental concepts that students are initially exposed to while learning about macro-scale visible structures. Ideas about the relationship between structure and function are later applied to the atomic scale relationships in fields such as chemistry, biology, and other scientific fields. Since these ideas of the structure/function relationship are carried through many scientific fields, they are of high importance. ${ }^{3}$

Depending on the level of the students and their stage of development, some students may need to develop scaffolding with macro scale structures, and some may be able to imagine the relationships not visible at large scale, more on the cell level, or the scale of molds, mushrooms, and yeasts, which may require magnification to explore fully. This module aims to introduce basic fungal structures and their relationships to their function. Notes:

- Suggested correlating standards from the NGSS: 4LS1-1 Extending learned concepts of plant and animal structure and function to fungi ${ }^{3}$

- Ideal for student groups of any size

\section{Performance Goals}

After completing this module, students should be able to:

- Identify different structures of fungi

- Identify the function of basic fungal structures

\section{Pre-Lesson Sequence Preparation}

(1 week prior to the full lesson sequence)

Teacher preparation: Slice up an apple into segments, making sure to have enough for each student to get a slice. Each apple segment should be placed in a clear sealable plastic baggie and labeled with a student's name.

This is a short preparation segment and shouldn't require much class time. In class, students should be given the citizen science soil collection kit along with a bag containing their slice of apple. After exploring the contents of the citizen science kit, students are expected to discuss the best place accessible to them for sample collection based on the suggested collection criteria (https://youtu.be/ntO2pAuat5k). Students should be asked to go home and collect a sample from these types of locations. The students should be asked to take their apple slice, and add a pinch of soil taken from the same sample 
collection area. Students should be encouraged to record data in their science notebooks about the location of each soil sample and the apple's initial appearance.

*After each group returns with their sample and slice of apple - they will be required to follow these steps:

1. Label their plastic baggie with their name if it is not there already.

2. Make sure their data was recorded about their sample collection conditions (use inquiry-driven terms including where, when, etc.)

3. Seal the baggie and hand it to the teacher. Teachers may wish to supervise this process to ensure each bag remains sealed.

The apple should remain moist to encourage fungal growth. An apple is chosen arbitrarily and could be substituted for berries, tomato slices, or slightly moistened bread. The teacher should leave the sealed bags in a spot they can remain undisturbed under room temperature conditions.

\section{Materials}

- Citizen Science Soil Collection Program educators kit, which can be obtained here https://whatsinyourbackyard.org/educate

- Provided images and worksheets to put in the science notebook

- An apple or two that can be sliced (or other matrix likely to grow molds)

- Plastic baggies that are sealable

- Either tape and pen, or sharpie to label

- Light and dark construction papers

- A cup or bowl to cover each mushroom

- An assortment of store-bought mature mushrooms

- Some mushrooms are easier to produce spore prints from than others, if purchasing mushrooms instead of growing them yourself ${ }^{3}$, a bit of research may be necessary to verify which varieties are available to you and work best. Farmers' markets and online retailers are also good sources for mushrooms.

- Use caution if using wild mushrooms. Some mushrooms can be extremely poisonous. If using wild mushrooms have students do the dissection activity with gloves on, under close teacher supervision. We strongly advise against the consumption of wild mushrooms unless identified or collected by an expert. 


\section{Optional Materials}

- Phone attachable macro lenses/microscope/magnifying glasses. These are useful for more detailed investigations and comparisons of micro vs. macro scale objects and structures (some examples are listed in the appendix). Magnification devices can often be purchased from "big-box" electronics retailers or from online phone/camera accessory providers.

In the classroom (Suggested duration: 20- 30 minutes of in class time, once a day over 4 days to a week.)

Engage: Part 1 - a focus on refreshing older concepts - The teacher opens class with a display of close-up images of plant and human structures. The focus should be on visible external structures like limbs or leaves rather than internal structures like organs or cells. Students are asked to guess at what structure the image is, and then discuss the function that structure plays. The teacher should then ask if anyone can volunteer an example of other biological structures and their functions.

Once students demonstrate knowledge of animal and plant structures, the teacher should display several images of fungi and ask students to guess what the new images show. Some fungi, like mushrooms, will be easier to identify than others, such as molds and yeasts. Some example images are provided in section 3 of the appendix.

Part 2: Using the images of the fungi, the instructor should prompt discussion about what fungi are (all the images you just showed the class) and where they can grow (not just in forests and old food, but almost everywhere!) After class discussion, the fungi images should be reintroduced adding a full spectrum of mushrooms, molds, and yeasts.

The teacher could include the fact that a distinguishing characteristic of many fungi is that, although some fungi look like plants, they are unable to make their own food, which is why they must draw nutrients from external sources.

Explore: The class should be divided into small groups of 3 to 5 students. Images of some of the culture plates from the Citizen Science Soil Collection Program lab can be projected or shown digitally for students. Allow students to record their observations in a lab notebook. Alternatively, the images can be printed in color with large size (one per page) and laminated to make a physical class set. The images have to remain large and in color if printed in order to be able to see the relevant differences such as texture. Some good example images 
are linked in the appendix. Within this activity, students are expected to look at images of an agar plate that has fungi growing on it, and differentiate how many distinct types of fungi they see on each. The teacher should allow students to come up with their own criteria or reasons to classify each as "different" and be asked to write out the categories to support their choices. Example methods of differentiation could include differentiation based on size, texture, color, and other features.

The images catalogued in the Citizen Science Soil Collection database (https://shareok.org/handle/11244/28096) includes pairs of the same soil sample grown on different media (fungus food). They also include data concerning where each sample was collected and when possible, the specific types of fungi obtained from each sample. (If you wish to look up more details on samples or just find sample images, perhaps from your area, check out this interactive map or search the sidebar with "in this project" selected to search by keyword) The teacher should encourage students to ask themselves why the same sample of dirt shows fungi that looks different on the different media (food) types. How might food select for different types of growth? Could the same fungus just look different on a different medium (yes!)? This is a good opportunity to work on good data collection and analysis methods by building data tables for each group, and then the class. What goes in the data table can either be decided by the class, or by the teacher beforehand. An important point to address with the class is the role of data interpretation - while the data remain constant, how a person views them can vary based on each person's imperfect knowledge of nature. This is true even for trained scientists.

Explain/Explore Lab 2: At this point, we hope that students have devised a few ways to differentiate fungi based on sight; color, texture, and size. Color differentiation mostly applies to fungi growing on the same medium as fungi present different morphologies based on growth conditions. Students can be asked to think about other cases where food quality changes the way an organism appears. Plants grown with different amounts or types of fertilizers offer some very interesting imagery. This means that you may have the same fungus on two plates and they will appear different under these non-equivalent conditions!

Texture is an important indicator to differentiate fungi. Texture gives us clues as to the structure of the fungi, even without magnification. For example, it's fairly likely that a fungus that has long, tall, hair-like filaments, on one medium is different from a fungus that appears as short, hair-like projections on another medium (although it is possible!). 
Lastly, size is reasonable criterion for evaluation. In some cases, fungi may appear very similar, but have different growth rates or maximum colony sizes that they can obtain. While there is no set range of sizes that all of one type of fungus falls within, it is possible to use extremes in size differences to delineate different types of fungi. Have the students think of other examples of size variations that distinguish items from one another. Examples could include different size fruits (like navel oranges versus clementines, or different varieties of tomatoes).

The instructor should ask students to wrap up their discussion and elicit group responses summarizing their data. Students should discuss what they found and how they divided the fungi. As students describe the different characteristics they observed in the images, the teacher should highlight groups that did exceptional job of differentiating fungi. Further discussion of the value of careful observations is helpful show students how recording and interpreting data is important to the scientific process.

It is unlikely that the students will come up with all the different structures fungi have, solely from the small-scale fungi like molds. This leads into a second lab where the students can explore a larger fungal specimen the mushroom dissection Lab.

For the mushroom lab, students should remain in their small groups. Each group is given a segment of dark and a segment of light paper, a bowl or cup, and a minimum of two mushrooms (they can be of the same type or a variety).

Students should be instructed to first draw their mushroom in its entirety. The teacher should then provide descriptions of a mushrooms cap, stalk, and gills and ask students to label them on their drawing. Next, the students should carefully separate the cap from the stalk, and place one cap gill side down, on each of the colors of paper. They should then be covered with a cup or bowl and left undisturbed for $12+$ hours.

After waiting +12 hours, the teacher should ask students to recall all the structures they have now learned. Definitions for the following structures should be provided to students along with images of each structure. Images can be sourced from examples provided in the appendix section 3 or found through other means.

- Hyphae- threadlike filaments that make up the body of the fungus

- Vegetative Hyphae - penetrates media (the food or material from which the fungus obtains nutrients and grows)

- Aerial Hyphae- above media surface

- Reproductive Hyphae- releases spores 
- Mycelium- collection of/network of hyphae

- Spore- Tiny reproductive structure released from the fungus (like tiny seeds)

The teacher should then explain that the mushroom the students dissected is the fruiting body of the fungus; it is the above ground part used by fungi to help spread spores. Continuing the lab, the students should be instructed to carefully lift their mushroom cap to see a spore print. While the spores are so tiny that we cannot see them individually with the naked eye, when enough spores collect on a surface, you can see them as a powdery image. Some fungi produce dark spores, some light, which is why the spore print shows up better on some colors of paper than others!

Interestingly, a mushrooms spore print is somewhat like a human fingerprint and is an important method for identifying some types of mushrooms!

Elaborate: While reminding students that they should remain sealed, the instructor should have students revisit the apple slices they prepared the previous week. Students should record their new observations in their science notebooks. Now that they are aware of fungal, structures student groups should report on their findings and use the introduced scientific terminology to report things as the color, size, and shape of the fungi that have begun to grow.

Students should be expected to theorize and discuss why different sample collection areas resulted in different molds growing on their apples, as well as why there are differences in the diversity of the fungi shown in the agar plates compared to what is present on apple slices. Even in relatively localized areas, such as samples collected from different backyards in the same neighborhood or even from different areas on the same property, many different types of fungi will occur. This is a good example of the diversity of fungi and sheer numbers of fungi living worldwide.

\section{After the lab}

The apple slices should be collected and disposed of by an adult. It is important that the bags remain sealed so that students do not come in contact with these enriched microbial habitats. In the event a student does open or touch a fungus-covered sample, have the student wash the exposed area thoroughly with soap and water. Some fungal spores can be harmful to human health, so it is important to not release the spores from the sealed environment. Proper 
disposal procedures include placing the sealed bags in a strong trash bag, and then disposing of it directly in an outside dumpster in an area away from students. This will help reduce accidental exposure to the fungi and their spores in case a bag is compromised. 


\section{Section 3. Decomposer Observer $\left(5^{\text {th }} / 6^{\text {th }}\right)$}

\section{Introduction}

In the classic model of the food web, energy transfer is followed through a cycle including abiotic factors (e.g., rocks, soil, sun, and others), as well as biotic factors (e.g., living organisms). Producers take energy from the sun, consumers gain energy by consuming either producers or other consumers, and then decomposers recycle and break down the remnants of the producers, consumers, and their respective waste. Students are often familiar with producers as plants and consumers as animals even if they aren't familiar with the more scientific terminology or exactly how actual energy transfer occurs. This knowledge can stem from personal observation or even relationships shown on television and movies. However, the role of decomposers in the food chain is often less familiar to students. This module aims to foster scientific skills and to increase student knowledge of decomposers (with a specific focus on fungi). Fungi include molds, yeasts, and mushrooms (which all fall under the umbrella term of decomposers). ${ }^{4}$

- Suggested correlating standards from the NGSS: 5LS2-1, MS-LS1-54

- Ideal for student groups of any size

\section{Background}

Decomposers are an interesting and essential part of the food web. While in general they are less visible in daily life, but they play a significant role in the maintenance of ecosystem structures. Decomposers include things like bacteria, protozoans, fungi, and some insects and worms (If you or your students want to learn more about decomposers, Crash Course kids provides a good segment on decomposers. ${ }^{4}$ ).

Decomposers like fungi factor into the energy transfer by breaking down the organic waste from other parts of the food web, and effectively recycling that waste by releasing nutrients back into the environment. They are invaluable in preventing the buildup of useless waste in ecosystems and for allowing new organisms to grow.

Fungi such as molds are more likely to grow on substrates that have lower acidity, low preservatives, adequate moisture, and carbohydrates. Some of the decomposer fungi that work well in the classroom prefer environments on the warmer side (just like us!); however, room temperature is more desirable than extreme cold. This means that foods like berries and other fruits, sliced tomatoes, and fresh bread are likely to grow fungi, but dried strawberries, 
citrus, toast, or frozen foods aren't. Of course, just like most fields of biology and science, there are plenty of exceptions to these general guidelines (which might be fun to research as a bonus project!).

\section{Performance Goals}

After this module, students should be able to:

- Connect the role of fungi as decomposers to energy transfer in the food web and be able to define other participants in the food web

- Demonstrate knowledge of what factors contribute to creating an environment that is conducive to fungal growth

- Demonstrate knowledge of some preserving methods to keep food from spoiling by interfering with decomposers

\section{Pre-Lesson Preparation (1-2 weeks before in class lesson)}

A teacher or an instructor should first use the suggested criteria to select a variety of food samples and place them in individual sealed containers. It is important to do your best to ensure the container becomes both a sealed environment (for safety) and remains in conditions conducive to fungal growth (to make sure the experiment produces results).

Each container should be labeled to identify the item placed inside and the date that it was sealed. Pictures should be taken of the contents in each container including when the container was sealed, halfway through your experiment, and at the end of the test. However additional pictures (if possible) are encouraged because it provides a better means for interpreting change over time and offer additional educational value as talking points. An ideal 2 week schedule (if time permits) would consist of a picture every three days, such as starting on a Tuesday- Friday- Monday- Thursday- and then finishing in class on the following Monday.

If your class has lots of time, this entre module is easily modified to be done entirely in class. Photographs could be substituted with daily observational drawings by students and entries in a scientific notebook. Note that some food items may decompose more slowly and therefore a longer (3-4 week) timeline may be used. Instructors are encouraged to perform a trial run of selected foods to make sure that the items that are selected perform as expected.

\section{Materials}

- Several containers that are clear and sealable 
- (Suggested: Mason Jars, Clear Tupperware, Gallon size plastic bags - make sure the containers are large enough to provide plenty of oxygen - remember that many decomposers require oxygen to do their job)

- Some varying types of food conducive to fungal growth

- (Suggested: Sliced fruit like strawberries or apples, applesauce, bread)

- An item NOT conducive to fungi growth.

- (suggested, food containing a larger quantity of preservatives such as a cheese puff or cupcake, dry or processed foods such as toast or freeze-dried fruit)

- Citizen Science Soil Collection Program educators kit, which can be obtained here -> https://whatsinyourbackyard.org/educate

- Provided worksheet

\section{Optional Materials}

- Salts, vinegar, and other preservative materials,

- There are many relationships between fungi growth that are worth exploring. As extra material, it may be interesting to have students try and preserve the food, and compare results, or compare already preserved to fresh version of food (fresh strawberries, strawberry jam, dried strawberries, frozen strawberries-kept frozen during the test). The historic relationship between our society and fungi is long and complex; there are many cultural behaviors relate to food preservation found throughout the world so there's a lot to explore!

In the classroom (Suggested Duration: 1-2 hours of classroom time)

Engage: The instructor should begin this module by showing students pictures of a mixture of perishable and non-perishable foods and asked students whether they are perishable or not. After students come to a consensus and identify perishable foods, they should be asked to think about why these foods go bad (decompose).

The teacher should remind students that we can sometimes tell that stuff has gone bad by seeing things that begin to grow on their surfaces. The teacher should explain that many times food goes bad because things like bacteria and fungi (mold) begin to grow in or on them and break them down. The teacher can then briefly explain that these fungi and bacteria that spoil food belong to a group of organisms collectively referred to as decomposers and that decomposers are an integral part of the food chain. It should also be noted that decomposers cover a wide range of organisms such as bacteria, fungi, and soil-based invertebrates that break down organic materials. 
Explore: The images of the food items on DAY 1 should be shown to the students. Students should be asked to record their observations of the pictures of food samples that the teacher prepared. Students should be encouraged to identify the food in each container, record the conditions, and include any other data they feel is important related to the food or the environment it is in.

Students should then be asked to make predictions as to what will happen to the food samples over time. To guide these predictions towards meaningful answers, students should be encouraged to think about what has happened to food in their own home when left under similar conditions? They should also be told to consider what would count as similar conditions (time, temperature, container, humidity levels, and other factors) because those are all meaningful data. If they have personal experience, it will help them develop predictions of the outcomes. A good sample prediction would be detailed, such as:

"I predict that after [x amount of time] that [type of food] will have changed in these ways [insert prediction]. I predict this because of prior observations in which I saw a similar thing happen to [insert description of personal experience]."

Students should then be shown any additional sets of pictures the teacher feels are valuable (such as a halfway point) so that students can discuss whether they think they see a gradual or abrupt change. They should then be shown the actual containers that have been sitting at room temperature for 1 to 2 weeks and asked to make observations. They should answer, "What has happened? Were your predications right or wrong? Why do you think they were right or wrong? What happened to different materials and why do you think some things are more decomposed than others?"

Explain: It is important to help the students connect the ecological focus on decomposers with previous learning to ensure that their knowledge base about decomposers and energy transfer in ecosystems is accurate. At this point, the teacher should be working towards explaining the definitions of things in the food web such as the following:

- Abiotic factor - a nonliving condition or thing that affects an ecosystem and the organisms in it

- Biotic factor-any living component within an ecosystem

- Energy - often transferred in the form of food, gives biotic factors the ability to live, move, and reproduce

- Fungi - specific group of decomposers that feed on organic matter

- Decomposer - an organism, especially a soil bacterium, fungus, or invertebrate, that decomposes organic material 
- Producer - an organism that makes its own food, first level of the food web

- Consumer - an organism that gains energy by eating other components of the food web

This can be done more traditionally by the teacher providing definitions or in a more interactive card sort format. Students who are in grades younger than $5^{\text {th }}$ may need the extra support of being given the definitions outright. More advanced students, or those in higher grades, should have at least some familiarity with these terms and concepts from earlier standards. For students already possessing some familiarity with the terms, the interactive card sort provides more autonomous engagement and strengthens cognitive development of these concepts. The interactive method requires two sets of cards, one set of definition cards and one set of word cards. Working in small groups of 2-4 individuals, the students should be provided the two mixed up sets and asked to have their group match what they think goes together. Once each group is done, the teacher should ask volunteer what they think goes together and ask the class if they agree. When an accurate consensus is reached, the definition is accepted and recorded. When multiple groups disagree, the teacher should ask each group how they arrived at their decision and the whole class should discuss which definition is correct and why (if necessary the teacher can correct the students if they cannot decide).

After all the correct definitions have been matched, students should be asked to synthesize their new definitions and their knowledge of decomposers to place all the factors and the relationships between them in the food chain.

At the end of the science period, students are given the citizen science kit and told to look at the criteria for a good sample collection location. After obtaining teacher or parent approval for a location, the students should be asked to take the kit home to collect a sample. As they are collecting their samples, students should describe (draw and describe) what they think is an example of the food web in that location. Effort should be made to include each element of the food web to identify energy inputs and output (e.g., in my backyard, grass is a producer, the bird is a consumer, the rocks are an abiotic factor, the fungi and worms are decomposers).

*Important note- restrictions may apply to doing the soil collection on a school's campus (public vs. private land laws). Encourage students to collect a sample at their own homes. It is also important that the collection form is filled out and signed so that each sample can contribute to the lab research! Refer to our website https://whatsinyourbackyard.org/ for details on collection guidelines and restrictions.

Elaborate: As an activity aimed at generating additional conceptual connections, the teacher can reintroduce the samples from the explore phase. Students should be asked to look at the samples before decomposers affected 
them and place them somewhere in the food web. Follow up would include asking students if they see a relationship between the rate of decomposition and where it belongs in the food web, and to describe that relationship.

Additional concepts that can be introduced are related to the foods used that were resistant to fungal growth. When returning to look at the food samples, the teacher may opt to focus on the foods that did not decompose. Some suggestions to help them identify preserved foods are to ask students to find samples that defied predictions or did not fit into emerging patterns. At this point, the instructor can introduce concepts of food preservation and other common methods that extend the shelf life of foods and how they interfere with the processes by which decomposers work. Students may be able to come up with some of these criteria themselves by discussing how prepared foods differ from biological materials in the environment.

Evaluate: As a review, students are asked to recall the different components in the food chain: consumers, producers, and decomposers, and give examples of each. This should focus on the following:

- Considering the decomposers, what is their role in the food web?

- Students should be able to develop ideas about decomposers, which don't make their own food. Instead, they breakdown organic materials at different stages in the food web.

\section{After the lab}

An adult should carefully dispose of the container in which the fungi were grown when students finish the lab. While encountering dangerous fungi is unlikely, some fungi could be harmful to human health. To be safe, the container should remain sealed once the food is placed in them. Proper disposal procedures include placing the sealed containers in a strong trash bag and then placing the bag in an approved trash disposal area away from students (such as a dumpster or lidded receptacle). This will help prevent leakages and accidental exposure. 


\section{Section 4. Synthetic and Natural (Middle/High School)}

\section{Introduction}

The modern world has countless inventions that do a myriad of different things. It seems that for many issues requiring a designed structure, an engineered solution has been created or research is underway to improve upon current designs. There is a strong need for students who are knowledgeable in scientific areas that can help design solutions to yet unmet needs, as well as address newly emerging problems.

Many organizations recognize the need to carryout student training and education in the sciences in order that society will be prepared to address humanity's future needs. These organizations include the National Research Council, College Board, and the developers of the Next Generation Science Standards, which all stress the fundamental importance of the relationship between form and function. In both natural systems and in synthetic design, understanding the basics of form and function, and how manipulating one can change the other, is vital to understanding organisms, systems, and objects at any level of organization.

The aim of this module is to introduce students to the potential natural products have to become highly useful synthetic products, and the necessity of research into these new synthetic products, as well as the important connection between form and function.

- Suggested correlating standards from the NGSS: MS-PS1-3 ${ }^{5}$

- Ideal for student groups of any size

\section{Background}

One of the applications of research into naturally derived products is in the medical field. Many diseases lack effective cures such as cancers or diabetes. Naturally derived products are being investigated as a resource to help find treatments intended to replace less effective approaches. In the fewer than 100 years since antibiotics were discovered, many bacteria have developed resistance against common treatments. Drug resistant strains of bacteria can cause incredibly deadly infections. Consequently, many researchers are actively searching for new antibiotic therapies that can control bacteria and avoid established resistance mechanisms. This problem is being 
tackled using a combination of approaches aimed at finding new treatments, as well as changing the structure of old antibiotics to regain their former effectiveness. ${ }^{5}$

How are scientists able to modify available drugs and turn them into new medical treatments? In the field of drug research, this can be accomplished by changing the structures of compounds at a molecular level - by arranging atoms in new ways, these synthetic compounds can sometimes provide enhanced properties of improved activity and reduced resistance. These same ideas can be applied to other chemically-driven fields. For example, in the fields of plastic polymers, the manipulation of atom content and order can enhance their properties to create new and useful materials.

\section{Performance Goals}

After this module, students should be able to:

- Understand that synthetic products are often derived from natural products

- Develop research skills and be able to write a rudimentary scientific research paper

- Elaborate on the importance of natural products in many scientific fields

\section{Pre-Lesson Preparation - None}

\section{Materials}

- Citizen Science Soil Collection Program educators kit, which can be obtained here -> https://whatsinyourbackyard.org/educate/\#scroll

- Internet Access

In the classroom (Suggested Duration: 2 hours over a period of one week)

Engage: To begin this module, the instructor should facilitate discussion of the current leading illnesses in the United States. Cancer, diabetes, and drug resistant bacterial infections are all major health issues that yet, lack fully effective cures. Biomedical research into new treatments for these diseases is important, especially for those who suffer from these diseases.

The instructor should ask the students what they know about biomedical research and where they think that treatments for other illnesses have been found. While details about the laboratory methods used for this type of research probably beyond most students' knowledge base, the aim is to get 
them thinking about these processes and concepts by asking these types of leading questions.

The teacher should then ask students what are "natural products" or "natural resource." It may depend on the classroom, but you should expect specific answers like water, plants, rocks, animals, sunlight, or oil, as well as vague definitions like "something that can be found in nature". A natural product is anything that nature can produce on its own, without human intervention, although humans may influence that production or treat these natural products in some way to increase their usefulness. For example, the cow milk many people consume is a natural product. It can be produced without human intervention. However, because it is a useful product, its production is amplified in agriculture and it is often extensively treated by being pasteurized or filtered for the purposes of extending its shelf life or ensuring it is safe to consume.

The next question posed to students should be "What is a synthetic material or resource?" Some examples of possible answers would be chemicals, rubber, plastics, medicine, or "things humans/scientists/engineers have made or designed". A synthetic product is made by humans using methods different from the methods of production found in nature. This means that the chemicals or materials forming synthetic products may or may not be present in nature; they can be synthetic versions of a natural product. In defining a natural or synthetic product it is important to consider not just what it is, but also how it was produced.

The abundance of synthetic products encountered in our daily lives demonstrate how important scientific efforts devoted to their creation have been to modern societies; we couldn't function as we do now without them. Since they are so important, students need to understand how these products are derived. Many synthetic products come from an ordered series of events based on the scientific process and that much of the inspiration in these fields start from nature. What we want students to realize is that synthetic products used in everyday applications such as medicines are often synthesized from natural ones. Natural products serve as a starting point and their production can be mimicked or changed to modify their functions.

A good example to share with your class is penicillin. Penicilium species are naturally occurring molds that produce substances that have antibacterial properties. One of these substances is the antibiotic penicillin (note that, Penicilium species often make many types of natural penicillins). Penicillin is naturally produced by Penicilium fungi and it is purified from the mold for use as a medicine. Both the fungus and the compounds it makes are natural 
products. However, there are synthetic types of penicillin formed when scientists modify the structure of penicillin to give it new properties. In the case of penicillin, the natural product is quite sensitive to acid and it rapidly destroyed in the stomach if taken by mouth. Scientists have identified ways to convert penicillin into a new synthetic form that is more acid stable and can be given by mouth. Thus, natural products serve as the starting point for producing synthetic materials.

Explore: Students should be given the citizen science soil collection kit. The teacher should explain the purpose of the citizen science research and have the students explore the citizen science website themselves. Attempting to help find new treatments for diseases is a job for everyone who can help find new natural products. Students should be encouraged to participate in the citizen science program by contributing to this valuable search. Each new sample added to the natural product library offers the chance to find new compounds from nature for use in society.

\section{Explain:}

This module began by going over background information answering the questions of "What is a natural product? What is a synthetic product? How are they related?" and briefly touching on why synthetic products are important. Students were encouraged to participate in the citizen science project both to emphasize scientific methodologies and because this project contributes to understanding why natural and synthetic products are important. The next section aims to motivate students to participate in programs like this by answering the often-asked question, "Why should I care about doing this myself? Yes, synthetic products and medical research are important, but why me?"

The main scientific idea behind this module relates to properties of research labs and how synthetic products are designed. Scientists can analyze the properties of substances at a molecular level in a variety of ways. Researchers take promising natural products, determine their composition, and design, extract, and recombine substances within them to form new synthetic substances that have new functions.

Students may wonder why such important research is being done as a citizen science project, relying on volunteer samples, instead of by the lab scientists sequencing the compounds? Students may be able to come up with their own answers, but the two biggest reasons are related to time and scale of the project. If lab scientists only had their own sample collection to rely on, it would be near impossible to collect as many varied samples as citizen scientists 
can provide. Citizen science offers unique opportunities to amplify the scale of the research operation. The contributions of citizen scientists are invaluable because they increase the efficiency of the search process. Citizen scientists can collect samples from unique locations and give lab scientist the freedom to devote more time to working on analyzing samples for new drug-like natural products. This type of team work is found in many large science projects and this is what makes the Citizen Science Soil Collection Program so unique and special.

To emphasize the scope of the project, and thus the importance of student participation and engagement, the teacher should ask students to explore the online database, which contains records of submitted samples (https://shareok.org/handle/11244/28096). The interactive map shows the diversity of regions that have been sampled. By clicking on individual samples, it is easy to visualize the variety of fungi obtained from the different locations.

Just like the patterns of biodiversity observed for plants and animals, different types of environments will provide fungi that are unique to a given location. The sample collection is facilitated by citizen scientist participation which, makes it possible to effectively explore the natural products world.

\section{Elaborate/Evaluate:}

After explaining to students the value of their participation in science from the citizen science perspective, it is important to use that renewed engagement to deepen understanding of topics. In this section students will use research about the lab portion of science to return to the concepts such as the importance of synthetic products and structure and function. This section also develops scientific writing and research skills.

To finish up the module, students are expected to research synthetic materials. Students should pick a topic focusing on an important synthetic product or naturally derived product. Examples could include Kevlar (a synthetic material used in bulletproof vests), different types of polymers and plastics that have important societal applications, or different types of vitamins or medicine.

The teacher may want to have students write a short proposal detailing which product they are choosing and why, before getting started. If students have never done scientific research, directing them to find scholarly sources through resources such as Google scholar or local research librarians will be helpful. 
The aim of the research paper is to discover how a synthetic product was made (what chemical processes were used to modify or purify the substance) and which natural resources were used to make it. Does the product occur naturally or has its structure been modified to become a new object not found in the natural world? Additionally, students should be asked to discuss the impacts, both positive and negative, this product has on society. Why is it important? Why do we use this instead of other alternatives or the natural products themselves? These are all questions students should keep in mind when researching their synthetic material. These research skills are important for productive citizens, as they help us think logically, critically, and let us facilitate our own learning! 


\section{Appendix/ Further Resources}

\section{Resources relating to the $5 \mathrm{E}$ learning Cycle}

Summary of the 5E model - Brief explanation and introduction to what the parts of the model are, and what should be included in each phase (about 1 page).

"The 5 E's." Enhancing Education, Corporation for Public Broadcasting, http://enhancinged.wgbh.org/research/eeeee.html

Using the 5E model - A book from the NSTA that details example vignettes of using science and the 5E model in elementary students, particularly with picture books. This is a very good resource for elementary science teachers if you have the budget to obtain a copy.

Ansberry, Karen Rohrich, and Emily Rachel Morgan. More Pictureperfect Science Lessons: Using Children's Books to Guide Inquiry, K-4. NSTA Press, 2007.

Case study on effectiveness of $5 \mathrm{E}$ model - A source from a journal delineating the results from a case study on the usefulness of the $5 \mathrm{E}$ cycle.

Tzu-Chien Liu, et al. "The Effects of Mobile Natural-Science Learning Based on the 5E Learning Cycle: A Case Study." Journal of Educational Technology \& Society, vol. 12, no. 4, 2009, pp. 344-358. JSTOR, JSTOR, www.jstor.org/stable/jeductechsoci.12.4.344

About the BSCS 5E instructional model, history and effectiveness Link to the website of the creators of the model (the BSCS) with very in depth content on the history of the 5E model as well as the BSCS, featuring a lot of documents and videos.

https://bscs.org/bscs-5e-instructional-model

\section{Resources on citizen science/science lessons}

SciShow citizen science video - I highly recommend this video to all beginning citizen scientists. It briefly explains the history and what citizen science is, in a very entertaining way.

https://www.youtube.com/watch?v=SZwJzB-yMrU\&feature=youtu.be

Crash Course - Very useful learning videos, they have content extending through most educational fields.

https://thecrashcourse.com/ 
SciShow (Kids) - A science based learning video channel geared towards younger students. Highly recommended for brevity, as well as content value and engagement with the entertaining way content is presented.

https://www.youtube.com/user/scishowkids

Citizen Scientist/Kids discoveries - Articles showing past successes of citizen scientists and children in science. All of these are relatively short and worth sharing with students.

https://science.nasa.gov/science-news/science-at-nasa/2011/22apr_zooniverse

http://www.kavlifoundation.org/science-spotlights/crowdsourcing-universehow-citizen-scientists-are-driving-discovery\#.WjAk6LQ-dp8

http://theconversation.com/exoplanet-discovery-by-an-amateur-astronomershows-the-power-of-citizen-science-75912

https://www.livescience.com/47642-discoveries-by-kids.html

http://mentalfloss.com/article/26782/quick-10-10-amazing-discoveries-kids

3. Resources Relating to Structure and function/ Exploring Fungi

Correlating Standards

NGSS 4LS1-1

https://www.nextgenscience.org/dci-arrangement/4-ls1-molecules-

organisms-structures-and-processes

Open Learning Initiative (structure and function) - A learning module from the OLI that centers around the relationship of structure and function in biology. This is only around 2 pages of content, but it is good content and includes links to more exploration.

https://oli.cmu.edu/jcourse/workbook/activity/page?context=c09c798180020ca

$\underline{600 \mathrm{a} 1 \mathrm{~d} 2 \mathrm{dca} 16 \mathrm{ae} 1 \mathrm{e} 3}$

Interactive map of image sources - A map of past submissions received by the citizen science program. The map is linked to our database, so data can be found with a search bar on the left or by zooming in on specific regions. Data includes images for more recent submissions, as well as information on where the samples came from, and what was found in the samples.

https://shareok.org/handle/11244/28096

\section{Suggested images to print and laminate or share digitally}

Fairmont, NC https://shareok.org/handle/11244/28569

- Red RBM plate -6 isolates 
- Orange TV8 plate -7 isolates

Medina, Ohio https://shareok.org/handle/11244/29013

- Red RBM plate -6 isolates

- Orange TV8 plate -7 isolates

Norman, Ok https://shareok.org/handle/11244/28692

- Red RBM plate -7 isolates

- Orange TV8 plate -6 isolates

Auburn, Washington https://shareok.org/handle/11244/28485

- Red RBM plate -5 isolates

- Orange TV8 plate -5 isolates

Mushroom Growing Kits - These are just a couple examples of kits available to purchase to grow a variety of mushrooms indoor yourself or as a classroom. Needed growing times range from around 10 days to a few weeks. Prices can vary, but most of these kits linked below are around $\$ 20$.

- Fungi Perfecti (Based in Olympia, WA) http://www.fungi.com/shop/indoor-growing.html?isorc $=2$

- BackToTheRoots (Group focused on teaching about growing your own food instead of buying it)

https://backtotheroots.com/products/mushroomkit

Info on spore prints - These two sources are both very useful $\sim 1$ page summaries of some information about mushrooms and their spores, as well as spore prints (what spore prints are, why they are important, how to make them).

Kuo, M. (2006, November). Making spore prints. Retrieved from the MushroomExpert.Com Web site:

http://www.mushroomexpert.com/spore_print.html

Sheine, Sandy, and Maggie Rogers. "How to Make a Spore Print." NAMA, North American Mycological Association, www.namyco.org/spore_prints.php

Examples of smartphone attachable macro lenses- These types of lenses can be ordered from an online retailer such as Amazon or in stores like WalMart or BestBuy.

https://www.amazon.com/AMIR-Fisheye-Attached-Together-

Smartphones/dp/B0179JX8GC/ref=pd lpo vtph 107 bs t 1? encoding=UTF8 $\underline{\text { \&pc }}=1 \&$ refRID $=$ K1JT3AB5QWKS8G9ZQ70C

https://www.amazon.com/Universal-HD-Iphone-LensSmartphones/dp/B071DQWKXL/ref=pd_lpo_vtph_107_tr_t_2?_encoding=UTF $\underline{8 \& p s c=1 \& \text { refRID }=\text { K1JT3AB5QWKS8G9ZQ70C }}$ 
Examples of Images of Fungi- From Pixabay (A great resource for free creative commons usable images)
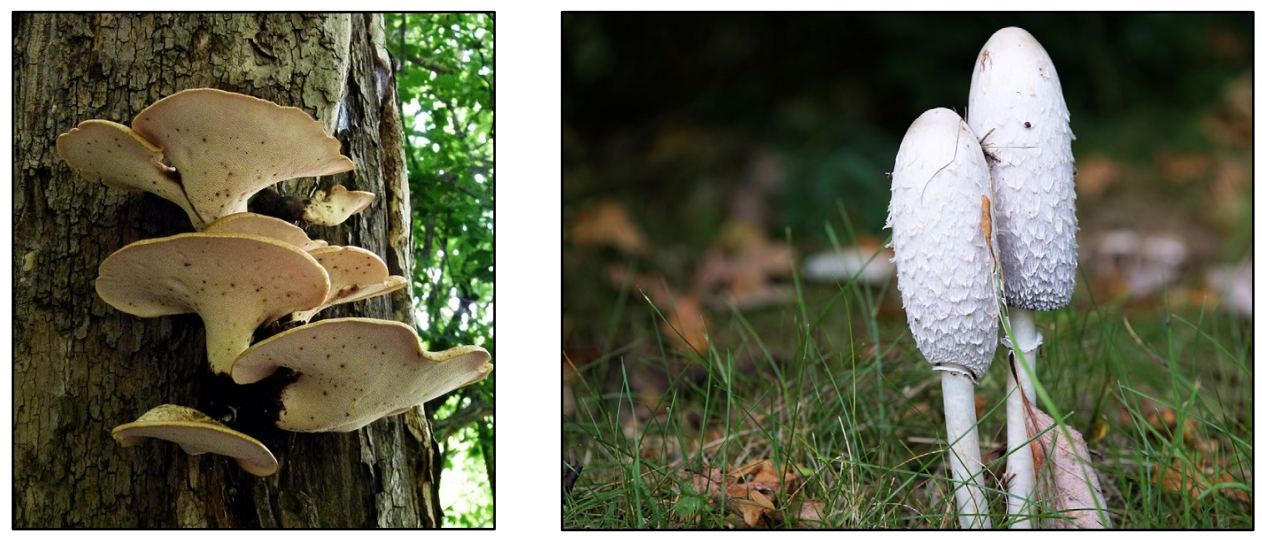

Mushroom Bracket Fungus. Licensed CCO.

https://pixabay.com/en/mushroom-bracket-fungus-fungus-2588950/

Mushroom Forest Autumn Nature. Licensed CCO.

https://pixabay.com/en/mushroom-forest-autumn-nature-2842171/
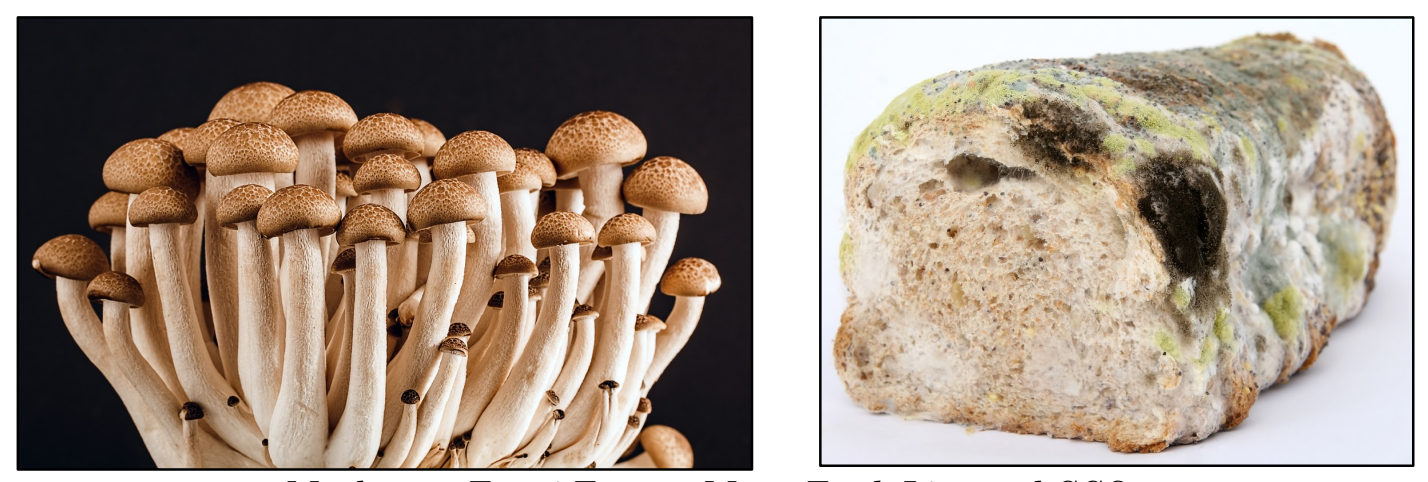

Mushroom Fungi Fungus Many Food. Licensed CCO.

https://pixabay.com/en/mushroom-fungi-fungus-many-food-389421/

Age Bacteria Bio Biology Bread. Licensed CCO.

https://pixabay.com/en/age-bacteria-bio-biology-bread-1238317/ 


\section{Fungi Structure Images- Stalk, Cap, Gills}

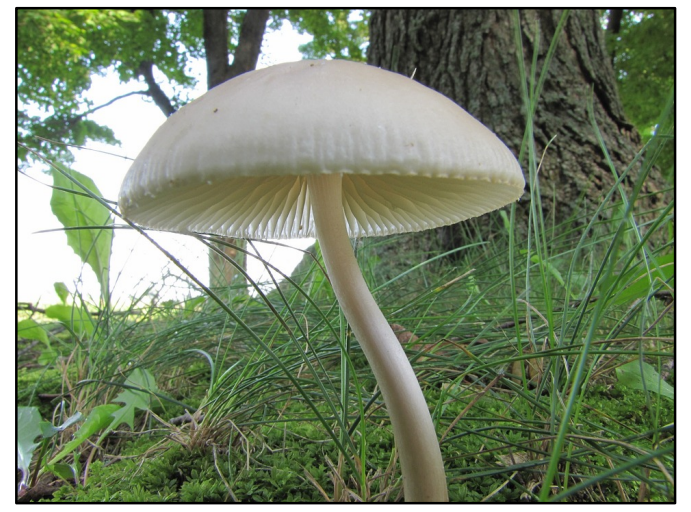

Mushroom Wild Fungi Nature. Licensed CCO.

https://pixabay.com/en/mushroom-wild-fungi-nature-1374048/

\section{Puffball Mushrooms- The "dirt or dust" is millions of spores}

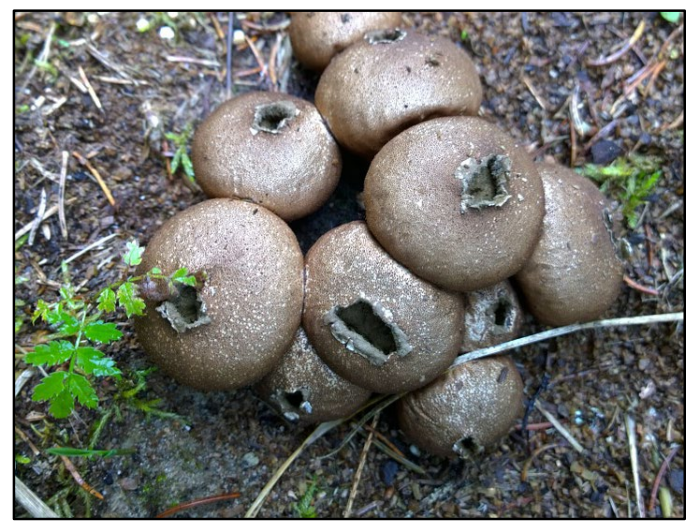

Puffball Fungus Mushroom Fungi. Licensed CCO.

https://pixabay.com/en/puffball-fungus-mushroom-fungi-968642/ 


\section{Resources related to Decomposers}

\section{Correlated Standards}

NGSS 5LS2-1

https://www.nextgenscience.org/sites/default/files/evidence_statement/

black_white/5-LS2-

1\%20Evidence\%20Statements\%20June\%202015\%20asterisks.pdf

\section{NGSS MS-LS1-5}

https://www.nextgenscience.org/pe/ms-ls1-5-molecules-organismsstructures-and-processes

Crash Course Kids Video On Decomposers - Highly recommend Crash Course and CrashCourseKids videos for the classroom in general. https://www.youtube.com/watch?v=uB61rfeeAsM

Northwestern ED Project segment on Decomposers- One page section on decomposers that is part of a larger module about the ecodome.

http://www.qrg.northwestern.edu/projects/MarsSim/SimHTML/info/wh ats-a-decomposer.html

Dirty Decomposers Lessons by Teach Engineering - Teach Engineering makes lessons around STEM topics. The introduction and background segments of this document are useful. Teach Engineering is also a good resource for additional science lessons! less\#

https://www.teachengineering.org/lessons/view/duk decomposers mary

PBS NOVA video on Decomposers - This short video is from an older NOVA educational documentary, with good images of some decomposers such as worms.

Video Adapted from Interactive NOVA: "Earth." Produced by WGBH in cooperation with NASA. Footage courtesy of the BBC. 1994, 2003 WGBH Educational Foundation https://www.pbslearningmedia.org/asset/tdc02 vid decompose/

\section{Resources relating to synthetic and natural products Correlating Standards NGSS MSPS1-3 \\ https://www.nextgenscience.org/pe/ms-ps1-3-matter-and-its- interactions}

Background on drug resistant bacteria - This is a good academic article on drug resistant bacteria. However, you may have to access this through an 
organization such as a public library if you don't want to pay for the individual article.

Andersson, Dan I. "Persistence of antibiotic resistant bacteria." Current opinion in microbiology 6.5 (2003): 452-456. http://www.sciencedirect.com/science/article/pii/S1369527403001127

Carnegie Mellon - natural vs synthetic polymers - Around 2 pages of content on synthetic and natural polymers, this is a good example of the difference between natural and synthetic. Basic background knowledge of polymers may be required.

https://www.cmu.edu/gelfand/education/k12-

teachers/polymers/natural-synthetic-polymers/

BBC Schools segment on synthetic materials - A short summary on natural versus synthetic materials from BBC Schools. BBC Schools is another good resource for educational content.

http://www.bbc.co.uk/schools/gcsebitesize/science/21c_pre_2011/materials/che micalscrudeoilrev1.shtml

Professor Dave Explains video "Will Synthetic Vitamins Make Me Explode?" - A short video designed for kids, explaining that natural doesn't mean good automatically and synthetic doesn't automatically mean bad.

https://www.youtube.com/watch?v=wioghkDpI_I

Encyclopedia Britannica on penicillin - Encyclopedia Britannica is always a good resource. This is a very in-depth discussion of penicillin and its history, it does use some academic or scientific terminology frequently, but is relatively easy to understand.

https://www.britannica.com/science/penicillin 


\section{Exploring Science!}

1. What is science? In the space below, draw a picture showing how you think science appears.

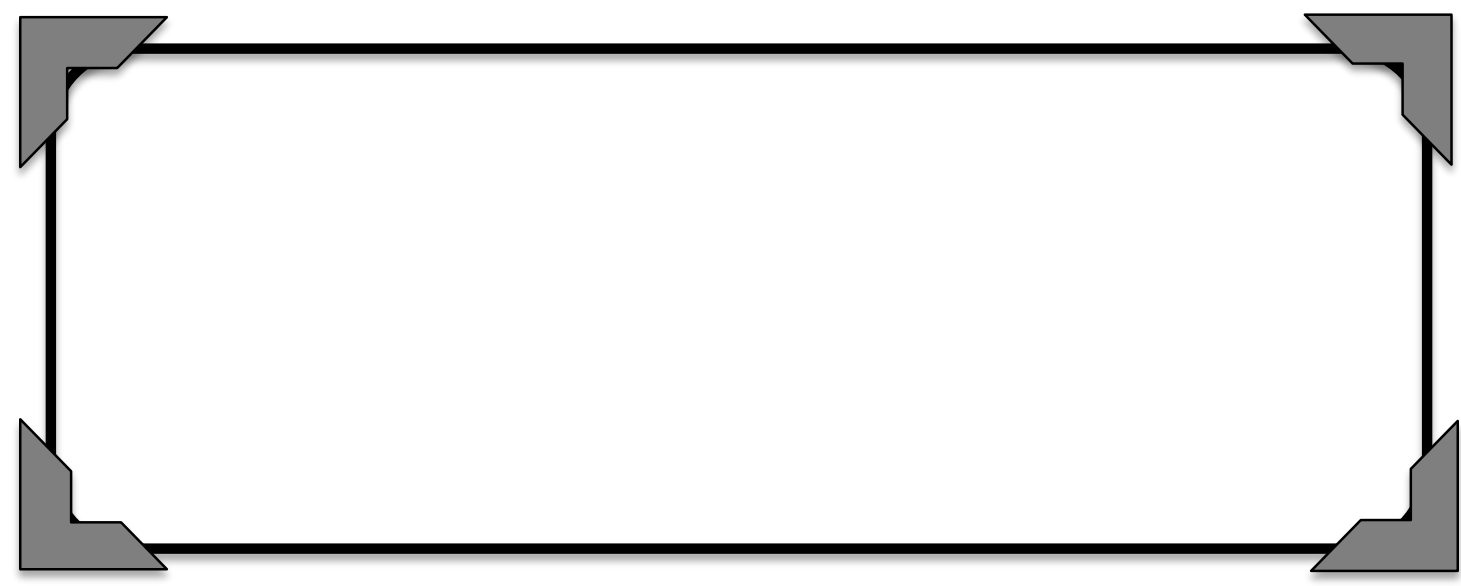

2. What is a scientist? In the space below, draw picture showing how you think a scientist appears in real life.

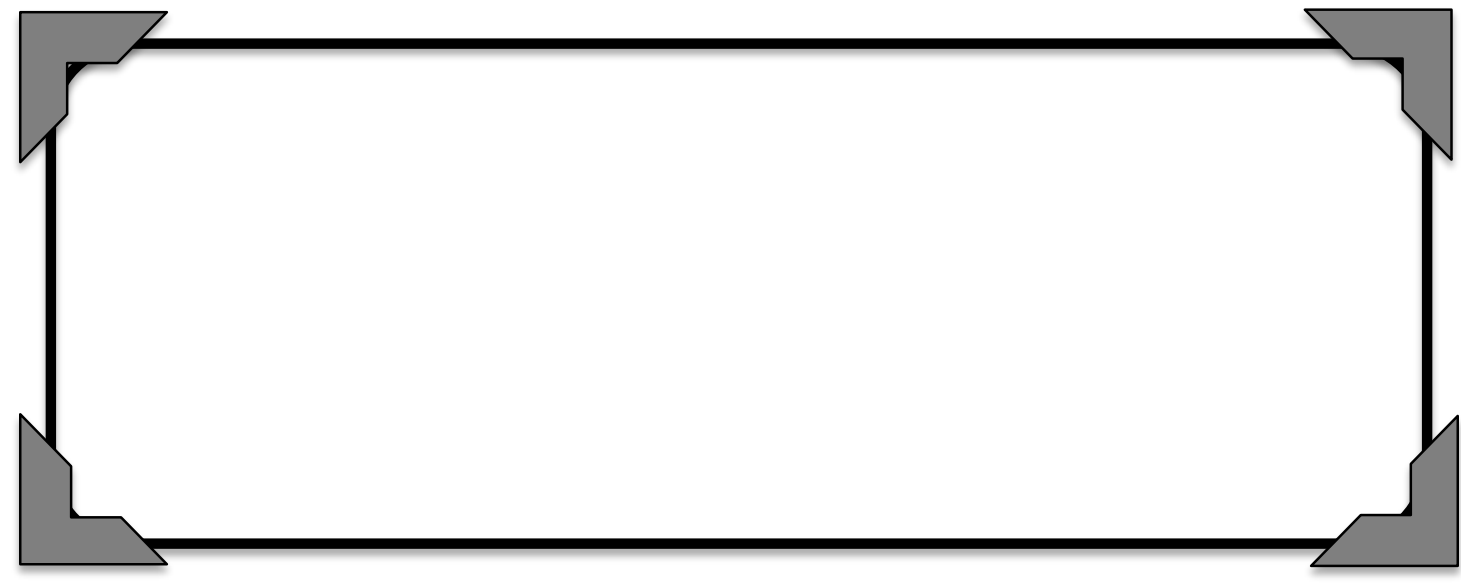

3. Summarize your class citizen science discussion below. Have your ideas about what scientists and science are changed?

\section{Science Is:}




\section{Exploring Fungi}

\section{Part 1-Apple slices}

\section{Procedure}

1. Read the instructions included with the soil sample collection kit. Be sure to focus on the criteria for selecting a good location to collect a soil sample.

2. As a group, discuss the types of areas that would meet those criteria. Discuss them and then choose a location to retrieve your sample and record your reasoning.

3. After your teacher approves the location, collect the project materials that you will need:

- A plastic baggie

- An apple slice

- A cup with a little bit of water in it.

4. Take the soil collection kit home and collect the soil sample.

5. AFTER collecting the soil sample, roll the apple slice in the same soil, sprinkle a few drops of water on it. Seal the apple slice in the plastic baggie.

6. Make observations of your apple slice and record them, label the bag, and return the baggie with the apple slice and the soil collection kit to your teacher.

7. Draw an example of the food web you see.

8. After several days your teacher will return your apple slice to you. Record your observations making sure to label the things that you see.
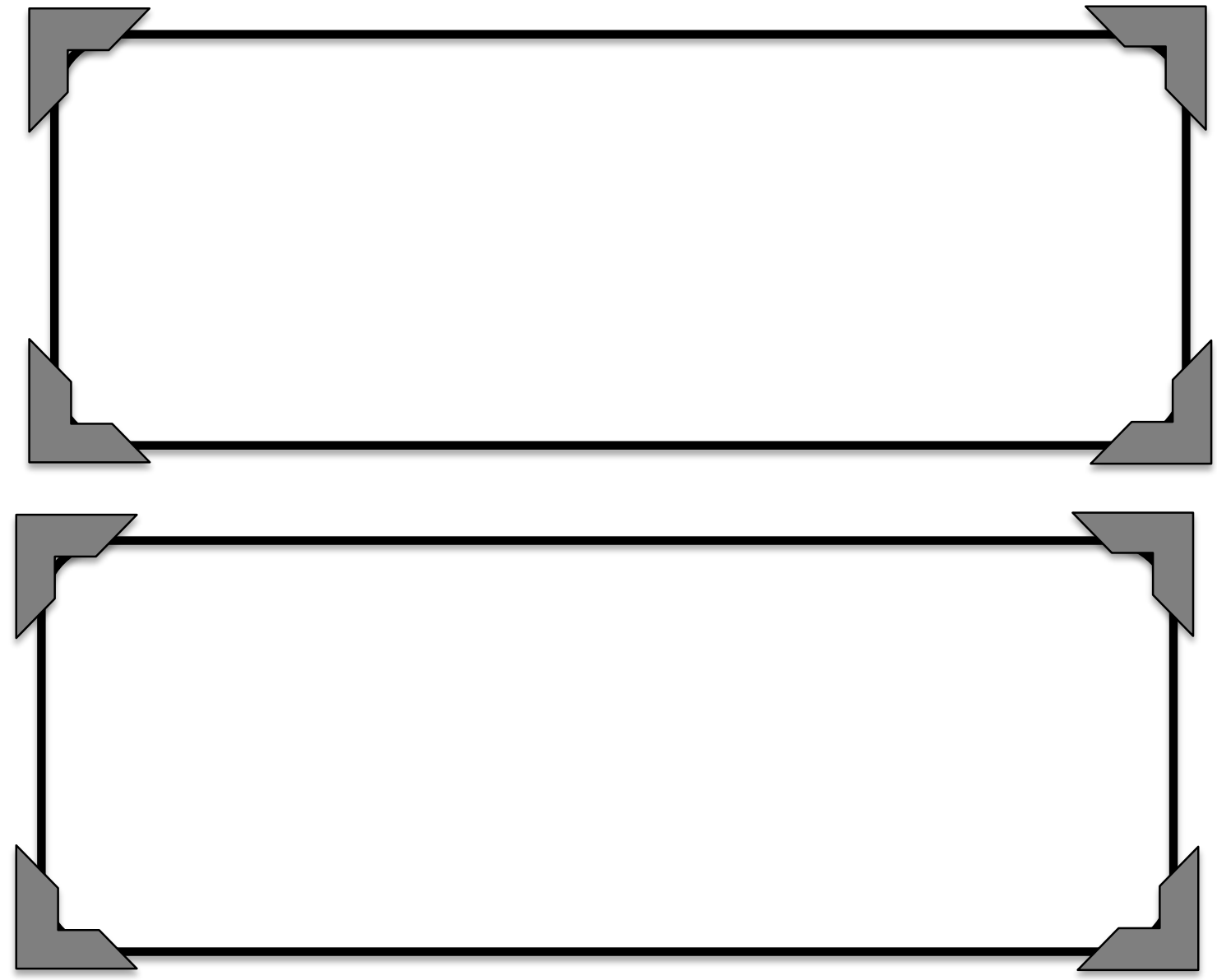


\section{Part 2- Mushroom dissection}

\section{Procedure:}

1. First make sure your group has all the materials you need

- Mushroom(s)

- Construction paper (light and dark)

- A cup or bowl

- Plastic knife

2. Once you have collected all the materials, draw and label that various parts of your mushroom(s) in the space below.

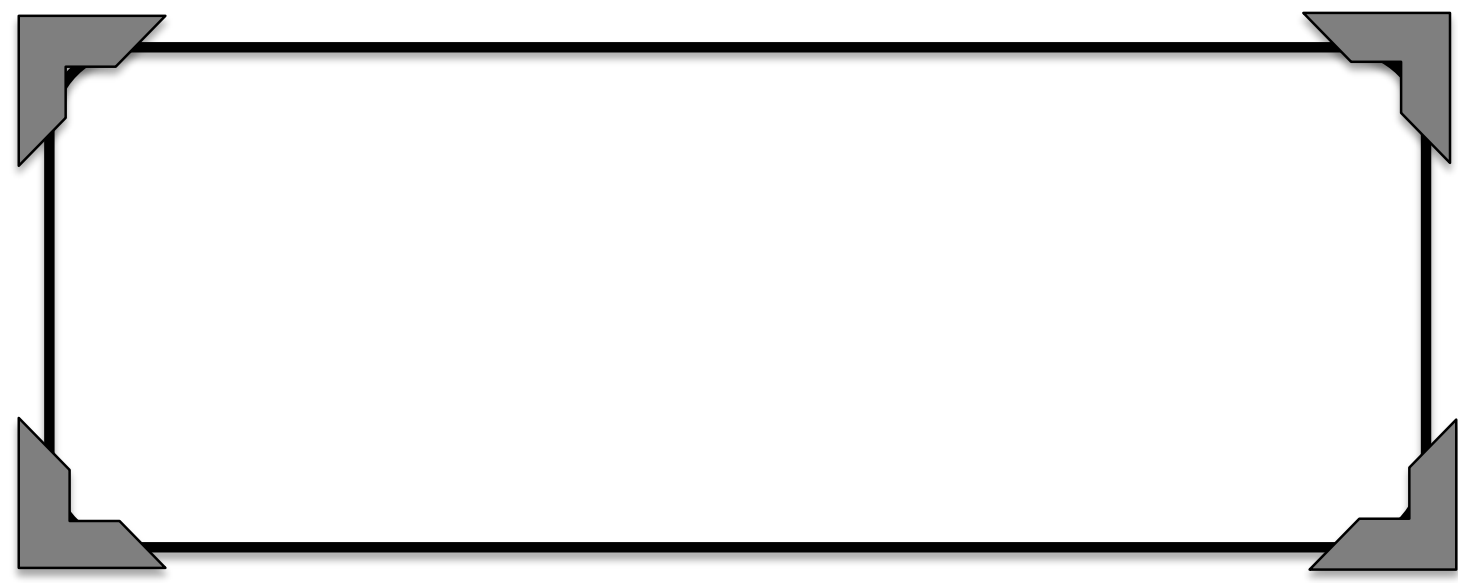

3. Once the drawing is complete, carefully use your knife to separate the stalk from the cap.

4. Place the cap gill side down onto the construction paper.

5. Cover the mushroom cap with the cup or bowl.

6. Leave the covered mushroom cap alone for 12 or more hours.

7. After the cap has rested, remove the cup or bowl covering it, and gently lift the mushroom cap from the paper. Draw what you see now on the construction paper below. Record any differences between what you see on the light and dark papers.

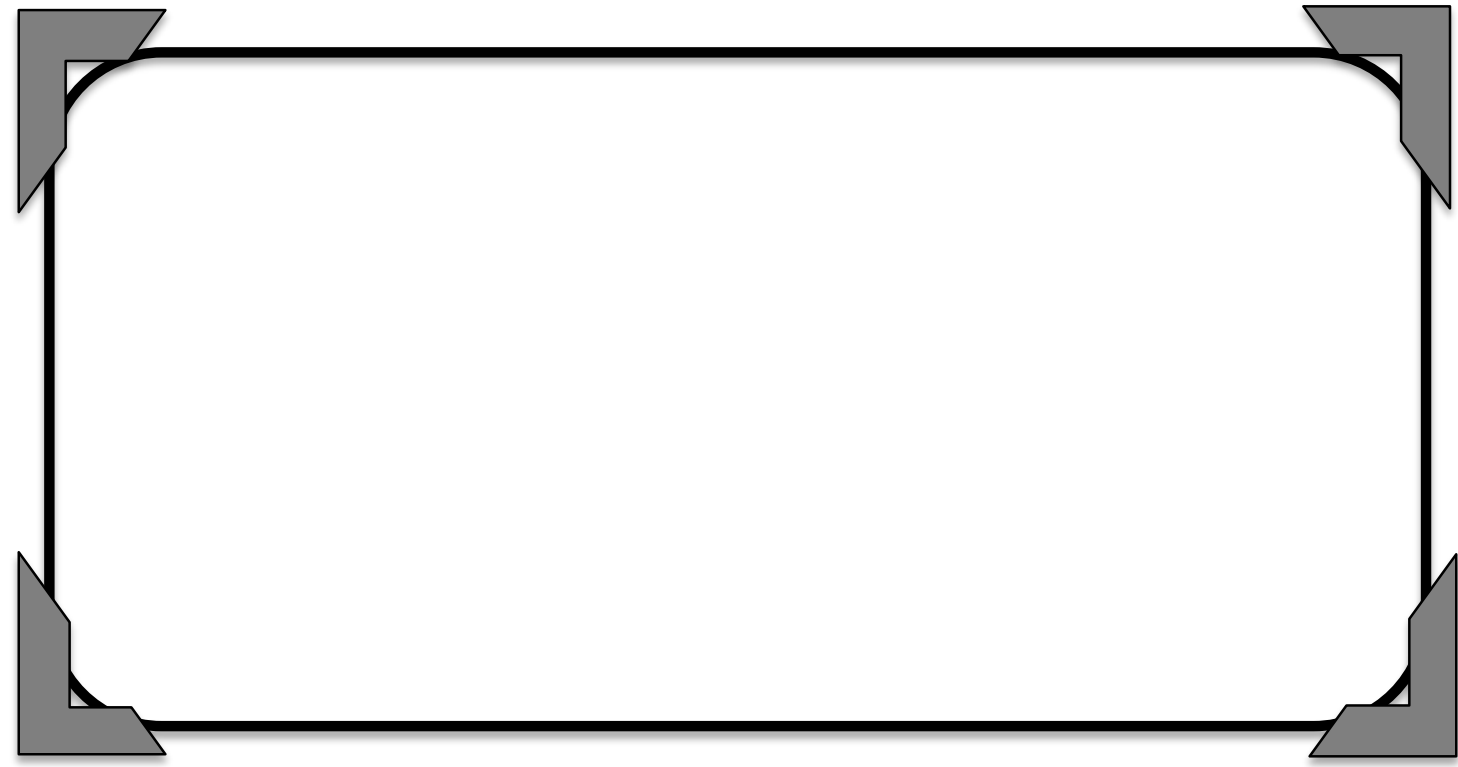




\section{Decomposer Observer}

\section{DAY 1}

Draw the food samples and record your initial observations of the foods and system.

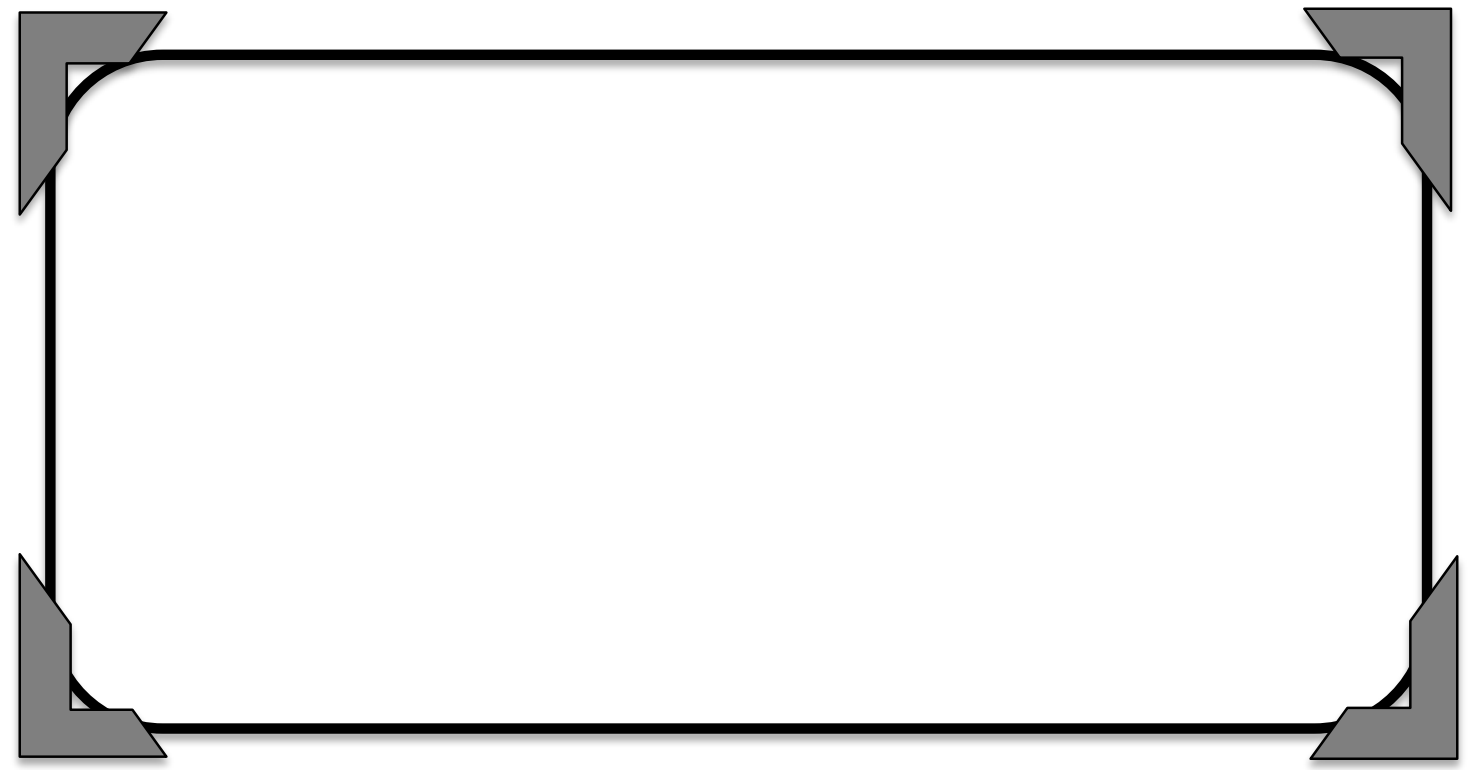

I predict that after days,

\section{AFTER DAYS}

After time passes, some changes will occur with the samples. Draw the food samples now that time has passed and record your new observations. Include whether your prediction was accurate. Why do you think that was the case?

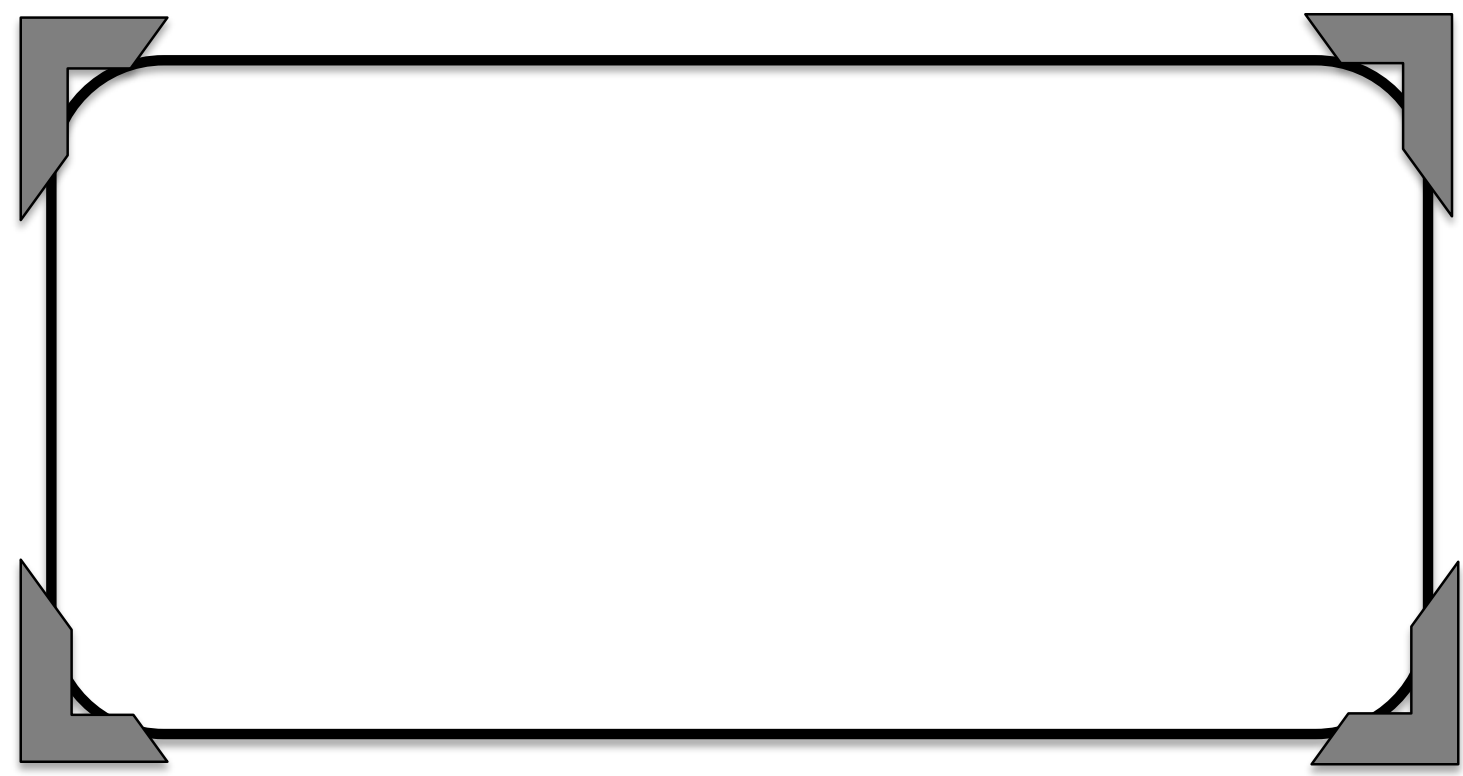

